\title{
The elephant in the waiting room
}

\section{How Canadian medical schools fail to represent individuals living in poverty}

\author{
Lucas Donato Dryhurst Foster
}

\section{INTRODUCTION}

In light of Premier Doug Ford's recent modifications to the Ontario Student Assistance Program (OSAP),${ }^{1}$ the prospect of obtaining a seat in one of Ontario's medical schools is becoming increasingly difficult for students of low socioeconomic status (SES). A degree of prescience is required to understand how these changes will influence the current social gradient within medical school, and how this may impact the care provided by Ontario's next generation of physicians.

Multiple studies have shown that the social gradient in doctorpatient communications negatively impacts the care provided to patients of lower SES. When interacting with these patients, doctors are less likely to inform and involve patients in treatment decisions and instead employ a more directive and less participatory consulting style. ${ }^{2-4}$ For decades, medical schools taught cultural sensitivity and awareness using the same techniques that were used to teach other medical competencies. However, despite popular belief, cultural competency is not something that can be taught within the medical curriculum alone. ${ }^{5-7}$ If medical schools wish to address the issues that face individuals of low SES, they must at least entertain the possibility of adapting the current admissions policies to improve representation for one of Canada's most at-risk student groups. ${ }^{8,9}$

\section{SOCIOECONOMIC UNDERREPRESENTATION IN CANADIAN MEDICAL SCHOOLS}

Current affirmative action policies, which focus primarily on ethnicity, ${ }^{10}$ have failed to improve the lack of socioeconomic diversity in Canadian medical schools. For example, almost 1 in 5 medical students come from a household within the top 3\% of Canadian incomes. ${ }^{11}$ And while the majority of Canadian households report an income of less than $\$ 60,000$ per year, less than a quarter of Canadian medical students fall into this category. ${ }^{12,13}$ This data paints a stark picture of medical school admissions processes that is skewed in favour of those who come from affluent backgrounds (Figure 1).$^{14}$ This systemic bias is not a product of income alone, but rather of SES more broadly; medical students are over 6 times more likely to have a parent with a master's or doctoral degree than the general population. ${ }^{11}$ Also concerning is the fact that these numbers have remained the same for the last 20 years. ${ }^{15,16}$ While it remains true that a significant proportion of the students admitted through current affirmative action policies are from disadvantaged backgrounds, ${ }^{11}$ more must be done to address the SES gap in Canada's medical schools.

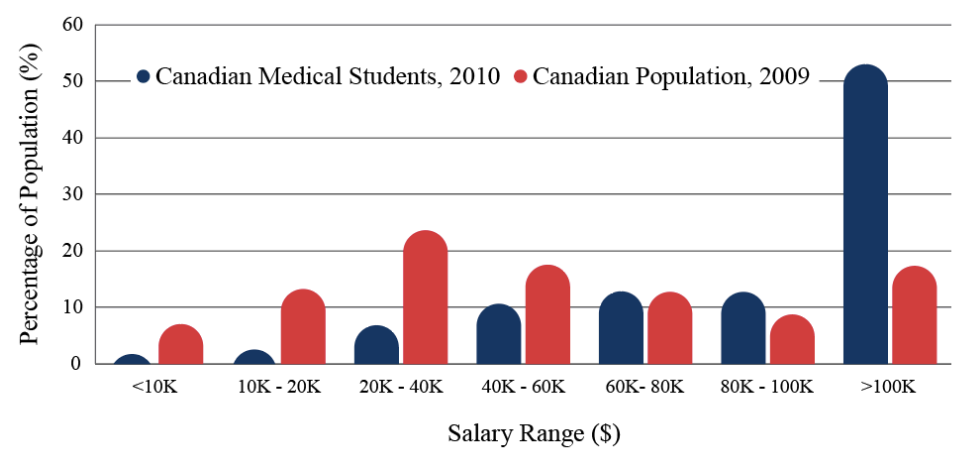

Figure 1: Distribution of income for Canadian Medical Students and the Canadian Population. Figure adapted from: The growing cohort of medical students in Canada: who are they and what career choices are they making? ${ }^{14}$

Currently in Canada, only the University of Saskatchewan has instituted a formal policy that specifically aims to increase representation for students from lower socioeconomic backgrounds. All other schools have relied exclusively on informal mentorship programs or ethnicity-based affirmative action strategies. ${ }^{10}$ It remains unclear why most medical schools, which place emphasis on developing "holistic" admissions processes, have not designed policies to encompass more SES-related factors that impact individuals' abilities to succeed in postsecondary institutions. ${ }^{10}$ The message that this sends to pre-medical students is ostensibly clear: economic disadvantages are only worthy of consideration if a student identifies with a specific ethnic group.

Poverty affects people of all backgrounds (some more than others), ${ }^{17}$ but it could be this very heterogeneity that makes it difficult for impoverished students to form a visible group that could be recognized by others as one that faces injustice. Ironically however, these students are more underrepresented in Canadian medical schools than African-Canadians, Indigenous students, and women (all groups for which affirmative action plans have an established political and legal precedent). ${ }^{10,12}$ To be clear, medical schools should not be advocating for a removal or replacement of current policies that support these groups; rather, they should be urged to contemplate the ethical double-standard that exists for both visible and non-visible minority groups and to consider the value of augmenting current policies with an SES-based approach.

\section{CONSIDERING AN ALTERNATIVE APPROACH}

The use of an SES-augmented admissions policy has faced significant resistance in the public sphere, ${ }^{18,19}$ though much of this has precipitated from failed attempts to use SES as a proxy for race. 
It has been reliably shown that excluding ethnicity as a criterion will reduce cultural diversity in the admitted class. ${ }^{20-22}$ However, it is imperative to resist the temptation to dismiss all SES-related factors in this vein, since a spectrum of possibility exists within the void that currently rests between SES-based and ethnicity-based affirmative action policies.

The merits of implementing SES-augmented admissions policies have been best exemplified by the University of Michigan's Law School, the University of California, Los Angeles (UCLA), and the University of Texas. The personal circumstances assessed in these programs include, but are not limited to, "ethnic origin, refugee status, family income, parental education, need to work, disadvantaged social or educational environments, and/or difficult personal situations."23 These policies have not only led to increased socioeconomic diversity within classes of admitted students, but have also been more effective at increasing ethnic and cultural diversity than their ethnicity-based alternatives. ${ }^{16}$ The students admitted through these programs were also more likely "to be the first in their families to attend college." ${ }^{11,24}$ These policies have an inherent ability to meet the changing needs of an increasingly diverse Canadian population, because they provide a dynamic platform upon which admissions committees can adapt the degree of emphasis that is placed on each of the aforementioned criteria.

An additional compelling argument for an SES-augmented approach is its ability to withstand both public and political scrutiny. Polls conducted by the Los Angeles Times, Newsweek, and EPIC/ MRA have all showed that readers were more than twice as likely to support SES-augmented affirmative action plans in comparison to race-only alternatives. ${ }^{8}$ Recently, tensions surrounding the use of ethnic affirmative action policies reached a pinnacle, as Harvard University's admission policies spurred a class-action lawsuit filed by Asian-American students. Despite achieving an ethnically "balanced" student body, it was discovered that if Harvard accepted students based solely on the applicant scoring in the top decile of the "academic index", the Asian-American population at Harvard would be $208 \%$ its current size. ${ }^{25}$ Many North Americans still consider the outcomes of strictly ethnic admissions policies to be ethically contentious, but developing an SES-augmented approach could safeguard the goal of having a socially-representative medical profession from the barrage of legal and political attacks that are beginning to unfold.

\section{CONCLUSION: MOVING FORWARD}

Unfortunately, affirmative action is not a therapy that can be prescribed to remedy society's inequalities. Even a perfectly designed admissions process may fail to adequately represent the diversity of a Canadian society, so the onus inevitably falls upon Ontario's medical schools to ensure that students are adequately exposed to social issues throughout their medical education. Continuing to develop a culturally and socially competent medical curriculum should remain a top priority for Ontario's medical schools as it will teach students to resist the notion that their role should be confined to that of a diagnostician or patient-care provider and encourage them to develop skills as a leader and a community advocate.
As with any other health issue, the solution to underrepresentation in medicine can and should be spearheaded by the medical community and cannot be left within the purview of politicians and other special interest groups. By implementing SES-augmented admissions policies, medical schools in Canada have the opportunity to give a voice to impoverished communities and to cultivate a generation of physicians that is sensitive to their unique health needs and personal issues. This would demonstrate that there is not just a place, but a very real need for students from disadvantaged backgrounds in medicine: from the perspectives they bring and relationships they foster, to the care that they will ultimately provide to the Canadians who need it most. Developing these policies is a necessary first step in the marathon of combatting systemic injustice and a symbol to society that physicians are beginning to address the elephant in the waiting room.

\section{REFERENCES}

1. Friesen J. Ontario Tories rolling back Liberal-era student-aid reform [Internet]. Toronto: The Globe and Mail; 2019 Jan 17 [cited 2018 Dec 1]. Available from: https://www.theglobeandmail.com/canada/articleontario-government-rolling-back-liberal-era-student-aid-reform/

2. Verlinde E, De Laender N, De Maesschalck S, et al. The social gradient in doctor-patient communication. Int J Equity Health. 2012 March;11(12):12. https://doi.org/10.1186/1475-9276-11-12

3. Willems S, De Maesschalck S, Deveugele M, et al. Socio-economic status of the patient and doctor-patient communication: does it make a difference? Patient Educ Couns. 2005 May;56:139-46. https://doi. org/10.1016/j.pec.2004.02.011

4. Rocque R, Leanza Y. A systematic review of patients' experiences in communicating with primary care physicians: intercultural encounters and a balance between vulnerability and integrity. PLoS One. 2015 Oct;10(10):e0139577. https://doi.org/10.1371/journal.pone.0139577

5. Haberman M. Can cultural awareness be taught in teacher education programs? J Teach Educ. 2006 Jul;4(1):25-32. https://doi. org/10.1080/1047621910040104

6. Chickering AW. The modern American college: responding to the new realities of diverse students and a changing society. San Francisco (CA): Jossey-Bass; 1981.

7. Byrd C, Post L. Does culturally relevant teaching work? An examination from student perspectives. J Student Diversity. 2016 Jul;6(3):1-10. https://doi.org/10.1177/2158244016660744

8. Thomas BR, Dockter N. Affirmative action and holistic review in medical school admissions: where we have been and where we are going. J Assoc Am Med Coll. 2019 Apr;94(4):473-6. https://doi. org/10.1097/ACM.0000000000002482

9. Diversity \& Inclusion [Internet]. Washington (DC): Association of American Medical Colleges; 2018 Feb. [cited 2018 Dec 1] Available from: https://www.aamc.org/initiatives/diversity/

10. Sequeira N, Coret A, Tan O, et al. CFMS report: socioeconomic diversity in admissions policy survey [Internet]. Ottawa: Canadian Federation of Medical Students; 2017 Feb. [cited 2018 Dec 1]. Available from: https://www.cfms.org/uploads/Socioeconomic\%20 Diversity\%20in\%20Admissions.pdf

11. Dhalla IA, Kwong JC, Streiner DL et al. Characteristics of first-year students in Canadian medical schools. CMAJ. 2002 Apr;166(8):102935 .

12. Walji M. Diversity in medical education: data drought and socioeconomic barriers. CMAJ. 2015 Jan;197(1):10-1. https://doi. 
org/10.1503/cmaj.141502

13. Greenberg L, Normandin C. Health at a glance: disparities in life expectancy at birth [Internet]. Ottawa: Statistics Canada; 2018 Oct. [cited 2018 Dec 1] Available from: https://www150.statcan.gc.ca/nl/ pub/82-624-x/2011001/article/11427-eng.htm

14. Slade $\mathrm{S}$, Busing $\mathrm{N}$. The growing cohort of medical students in Canada: who are they and what career choices are they making? Poster session presented at: 2012 American Association of Medical Colleges Physician Workforce Research Conference; 2012; Washington, DC.

15. National Physician Survey. Mississauga (ON): National Physician Survey; 2012. [cited 2018 Nov] Available from: http:// nationalphysiciansurvey.ca/surveys/2012-survey/

16. Table 11-10-0239-01: Income of individuals by age group, sex and income source, Canada, provinces and selected census metropolitan areas [Internet]. Ottawa: Statistics Canada. 2020 Jan. [cited 2018 Dec 1] Available from: www.statcan.gc.ca/tablestableaux/sum-som/101/ cst01/famil105a-eng.htm https://doi.org/10.25318/1110023901-eng

17. Snapshot of racialized poverty in Canada [Internet]. Ottawa: National Council of Welfare, Government of Canada. c2018. [cited 2018 Dec

1] Available from: https://www.canada.ca/content/dam/esdc-edsc/ migration/documents/eng/communities/reports/poverty_profile/ snapshot.pdf

18. Reardon SF, Baker RB, Kasman M, et al. Can socioeconomic status substitute for race in affirmative action college admissions policies? Evidence from a simulation model [Internet]. Princeton (NJ): Education Testing Service; 2015 Aug. [cited 2018 Dec 1] Available from: https://www.ets.org/Media/Research/pdf/reardon_white_paper.pdf

19. Bridges KM. Class-based affirmative action and the lies that we tell about the insignificance of race. Boston University Law Review. 2016 Apr;96(1):55-108.

20. Magnus SA, Mick SS. Medical schools, affirmative action, and the neglected role of social class. Am J Public Health. 2000 Aug;90(8):1197-201.

21. Kahlenberg RD. A better affirmative action: state universities that created alternatives to racial preferences [Internet]. New York City: The Century Foundation; 2012 Aug. [cited 2018 Dec 1]. Available from: https://production-tcf.imgix.net/app/uploads/2012/10/03175956/ tcf_abaa-8.pdf

22. Sander RH. Experimenting with class-based affirmative action. Journal of Legal Education. 1997 Dec;47(4):472-503.

23. How applications are reviewed [Internet]. Oakland (CA): University of California; c2018 [cited 2018 Dec 1] Available from: https://admission. universityofcalifornia.edu/how-to-apply/applying-as-a-freshman/ how-applications-are-reviewed.html

24. Brief for the United States as Amicus Curiae in Support of Respondents, 23 and 28, Fisher v University of Texas, 2015. Available from: https://legal.utexas.edu/scotus-2015

25. Rebuttal Expert Report of Peter S. Arcidiacono. Students for Fair Admissions, Inc. v Harvard, 2018. Available from: https:// samv91khoyt2i553a2tls05i-wpengine.netdna-ssl.com/wp-content/ uploads/2018/06/Doc-415-1-Arcidiacono-Expert-Report.pdf 